This is an electronic reprint of the original article. This reprint may differ from the original in pagination and typographic detail.

Author(s): Lettry, J.; Alessi, J.; Faircloth, D.; Gerardin, A.; Kalvas, Taneli; Pereira, H.; Sgobba, S.

Title: Investigation of ISIS and Brookhaven National Laboratory ion source electrodes after extended operation

Year: $\quad 2012$

Version:

Please cite the original version:

Lettry, J., Alessi, J., Faircloth, D., Gerardin, A., Kalvas, T., Pereira, H., \& Sgobba, S. (2012). Investigation of ISIS and Brookhaven National Laboratory ion source electrodes after extended operation. Review of Scientific Instruments, 83(2), 02A728. https://doi.org/10.1063/1.3680078

All material supplied via JYX is protected by copyright and other intellectual property rights, and duplication or sale of all or part of any of the repository collections is not permitted, except that material may be duplicated by you for your research use or educational purposes in electronic or print form. You must obtain permission for any other use. Electronic or print copies may not be offered, whether for sale or otherwise to anyone who is not an authorised user. 


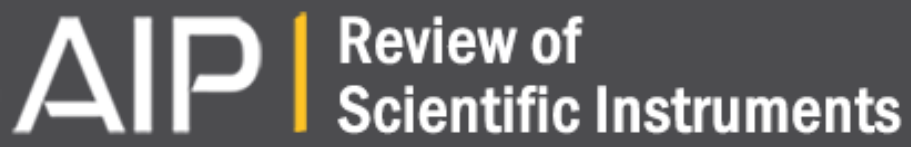

\section{Investigation of ISIS and Brookhaven National Laboratory ion source electrodes after extended operationa)}

J. Lettry, J. Alessi, D. Faircloth, A. Gerardin, T. Kalvas, H. Pereira, and S. Sgobba

Citation: Review of Scientific Instruments 83, 02 A728 (2012); doi: 10.1063/1.3680078

View online: http://dx.doi.org/10.1063/1.3680078

View Table of Contents: http://scitation.aip.org/content/aip/journal/rsi/83/2?ver=pdfcov

Published by the AIP Publishing

\section{Articles you may be interested in}

The characterization and optimization of NIO1 ion source extraction aperture using a 3D particle-in-cell code Rev. Sci. Instrum. 87, 02B145 (2016); 10.1063/1.4939202

Wave frequency dependence of $\mathrm{H}$ - ion production and extraction in a transformer coupled plasma $\mathrm{H}-$ ion source at SNUa)

Rev. Sci. Instrum. 83, 02A727 (2012); 10.1063/1.3678659

The Brookhaven National Laboratory electron beam ion source for $\mathrm{RHICa}$ )

Rev. Sci. Instrum. 81, 02 A509 (2010); 10.1063/1.3292937

High-intensity ion sources for accelerators with emphasis on $\mathrm{H}$ - beam formation and transport (invited)a)

Rev. Sci. Instrum. 81, 02B311 (2010); 10.1063/1.3272825

Extraction physics in volume $\mathrm{H}$ - -ion sources

Rev. Sci. Instrum. 77, 03 A502 (2006); 10.1063/1.2149367

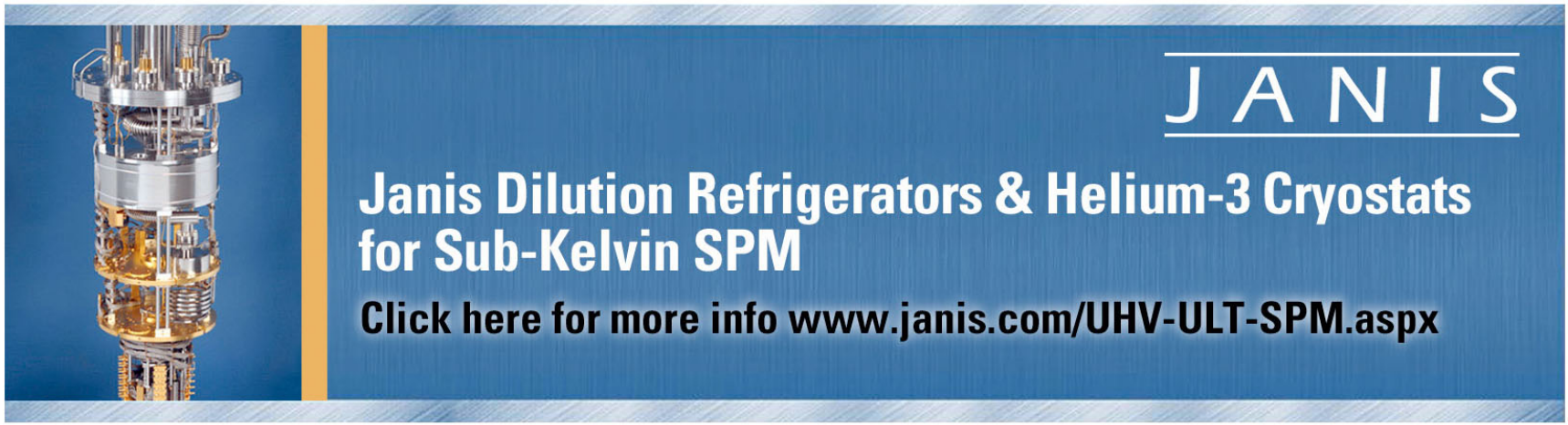




\title{
Investigation of ISIS and Brookhaven National Laboratory ion source electrodes after extended operation ${ }^{a}$ )
}

\author{
J. Lettry, ${ }^{1, b)}$ J. Alessi, ${ }^{2}$ D. Faircloth, ${ }^{3}$ A. Gerardin, ${ }^{1}$ T. Kalvas, ${ }^{4}$ H. Pereira, ${ }^{1}$ and S. Sgobba ${ }^{1}$ \\ ${ }^{1}$ CERN, 1211 Geneva 23, Switzerland \\ ${ }^{2}$ BNL, P.O. Box 5000, Upton, New York 11973-5000, USA \\ ${ }^{3}$ RAL, Harwell Oxford, Didcot OX11 OQX, United Kingdom \\ ${ }^{4}$ University of Jyvaskyla, P.O.Box 35, FI-40014, Finland
}

(Presented 13 September 2011; received 13 September 2011; accepted 15 December 2011; published online 23 February 2012)

\begin{abstract}
Linac4 accelerator of Centre Européen de Recherches Nucléaires is under construction and a RFdriven $\mathrm{H}^{-}$ion source is being developed. The beam current requirement for Linac4 is very challenging: $80 \mathrm{~mA}$ must be provided. Cesiated plasma discharge ion sources such as Penning or magnetron sources are also potential candidates. Accelerator ion sources must achieve typical reliability figures of $95 \%$ and above. Investigating and understanding the underlying mechanisms involved with source failure or ageing is critical when selecting the ion source technology. Plasma discharge driven surface ion sources rely on molybdenum cathodes. Deformation of the cathode surfaces is visible after extended operation periods. A metallurgical investigation of an ISIS ion source is presented. The origin of the deformation is twofold: Molybdenum sputtering by cesium ions digs few tenths of mm cavities while a growth of molybdenum is observed in the immediate vicinity. The molybdenum growth under hydrogen atmosphere is hard and loosely bound to the bulk. It is, therefore, likely to peel off and be transported within the plasma volume. The observation of the cathode, anode, and extraction electrodes of the magnetron source operated at BNL for two years are presented. A beam simulation of $\mathrm{H}^{-}$, electrons, and $\mathrm{Cs}^{-}$ions was performed with the IBSimu code package to qualitatively explain the observations. This paper describes the operation conditions of the ion sources and discusses the metallurgical analysis and beam simulation results. () 2012 American Institute of Physics. [http://dx.doi.org/10.1063/1.3680078]
\end{abstract}

\section{ISIS ION SOURCE AND OPERATION}

The ISIS operational ion source ${ }^{1}$ has successfully provided beam for the ISIS spallation neutron source for over 25 years. The $\mathrm{H}^{-}$Penning surface plasma source was first developed by Dudnikov ${ }^{2}$ in 1974 . The version used at ISIS comprises a molybdenum anode and cathode between which a low-pressure hydrogen discharge is produced (Figure 1). A transverse magnetic Penning field is applied across the discharge. The anode is hollow and has three equal-sized holes through which cesium vapor is fed from an oven via a heated transport line (held at $300{ }^{\circ} \mathrm{C}$ ) into one side of the discharge via two of the holes. Hydrogen gas is pulsed via a piezoelectric valve into the discharge via the third hole. The anode and cathode are housed in a stainless steel source body, the body is air cooled and the mounting flange is water cooled. The beam is extracted through a $0.6 \mathrm{~mm}$ by $10 \mathrm{~mm}$ slit in the aperture plate (plasma electrode). There is a $2.3 \mathrm{~mm}$ gap between the extraction electrode and the aperture plate. The source is pulsed at $50 \mathrm{~Hz}$. After extraction, the beam is bent through a $90^{\circ}$ sector magnet mounted on a refrigerated cesium trap and further accelerated by a post-extraction acceleration gap.

The ISIS operational ion source routinely produces $55 \mathrm{~mA}$ of $\mathrm{H}^{-}$ions during a $200-250 \mu$ s pulse at $50 \mathrm{~Hz}$ for

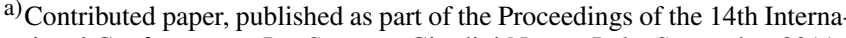
tional Conference on Ion Sources, Giardini Naxos, Italy, September 2011.

b) Author to whom correspondence should be addressed. Electronic mail: Jacques.Lettry@cern.ch.
}

uninterrupted periods of up to 50 days. The average lifetime of a source is about 21 days. Table I gives a summary of typical conditions for the operational source.

After only five days of operation, the signs of electrode surface wear become visible. The cathode surfaces start to show a redistribution of electrode material away from the two anode holes where cesium vapor is fed in. The material is redistributed on the cathode surfaces near the third hole in the anode where the hydrogen is delivered. This process is caused by $\mathrm{Cs}^{+}$ions sputtering the molybdenum surface after being accelerated by the cathode plasma sheath potential. A groove along the length of the anode also starts to appear. This is

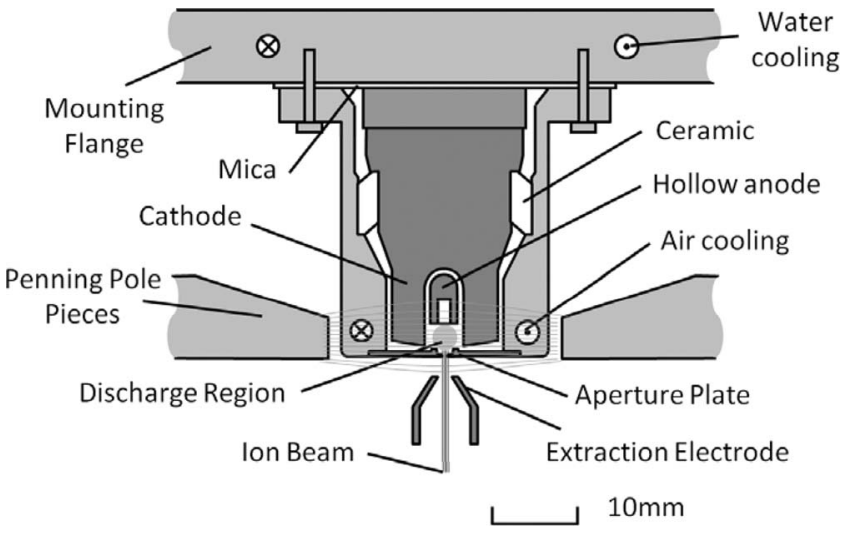

FIG. 1. A cross section though the ISIS Penning source. 
TABLE I. ISIS operational source running parameters.

\begin{tabular}{ll}
\hline \hline Discharge current & \multicolumn{1}{c}{$55 \mathrm{~A}$} \\
Discharge voltage & $60-70 \mathrm{~V}$ \\
Discharge pulse length & $600-800 \mu \mathrm{s}$ \\
Repetition rate & $50 \mathrm{~Hz}$ \\
Extraction voltage & $17 \mathrm{kV}$ \\
Extraction current & $100-500 \mathrm{~mA}$ \\
Extraction pulse length & $200-250 \mu \mathrm{s}$ \\
Cesium oven temperature & $160-190{ }^{\circ} \mathrm{C}$ \\
Cesium consumption & $\approx 3 \mathrm{~g} / \mathrm{month}$ \\
Hydrogen consumption & $10-20 \mathrm{ml} / \mathrm{min}$ \\
Electrode temperatures & $400-550^{\circ} \mathrm{C}$ \\
$\mathrm{H}^{-}$beam current at ground plane of & \\
post extraction acceleration gap & $50-55 \mathrm{~mA}$ \\
$\mathrm{H}^{-}$beam current at entrance to linac & $30-35 \mathrm{~mA}$ \\
\hline \hline
\end{tabular}

caused by sputtering from $\mathrm{Cs}^{+}$and $\mathrm{H}^{+}$ions being back accelerated across the extraction gap, through the aperture slit and hitting the anode. After about ten days, flaking and debris start to appear in the source. The loose flakes have the potential to partially block the aperture slit. This phenomenon results in a measurable step change in source output current. Very large flakes can occasionally short out the anode and cathode resulting in a complete loss of output. The inside of the aperture plate is also an anode for the plasma; after about 15 days, this surface also starts to show signs of wear. There are two ribs on either side of the extraction slit and these are slowly eroded away. Deposits of molybdenum starting to grow on the aperture plate are major source of flake debris. As the source ages further, the wear on the electrodes increase with more material sputtered away and redeposit in the source. After 30 days, there has been significant transference of electrode material.

To get a deeper understanding of how the electrode material is transferred, a very long lifetime source (\#48) was analyzed with a scanning electron microscope (SEM) at Centre Européen de Recherches Nucléaires. The source studied had run continuously with very constant operating conditions for 48 days. The current was stable between $31.5 \mathrm{~mA}$ and $33.5 \mathrm{~mA}$ and the electrodes temperatures slowly increased by $10{ }^{\circ} \mathrm{C}$ to $30^{\circ} \mathrm{C}$ as the source aged. The temperature of the cesium oven was kept constant at $164{ }^{\circ} \mathrm{C}$ and the hydrogen flow rate was kept constant at $17 \mathrm{ml} / \mathrm{min}$. The air cooling and water cooling were also kept constant as was the discharge duty cycle.

The cathode and extraction plate were investigated with the energy dispersive $\mathrm{x}$ ray and secondary electron imaging. Traces of cesium were only found inside the aperture plate. The cathode was cross-cut along a plane located half way between the anode tip and the extraction plate at $2 \mathrm{~mm}$ from the cathode end. Initially, the arc discharge plasma is populated with electrons, hydrogen, and cesium. $\mathrm{Cs}^{+}$ions will be accelerated to the cathode and via sputtering remove molybdenum atoms from the surface. The growth of the Mo-layer is shown in Figure 2. Two microstructures, different from the bulk, are observed. A crack is clearly visible between the bulk material and the deformed region. A micro hardness of $245 \mathrm{HV}_{0.1}$ in bulk material and $490 \mathrm{HV}_{0.1}$
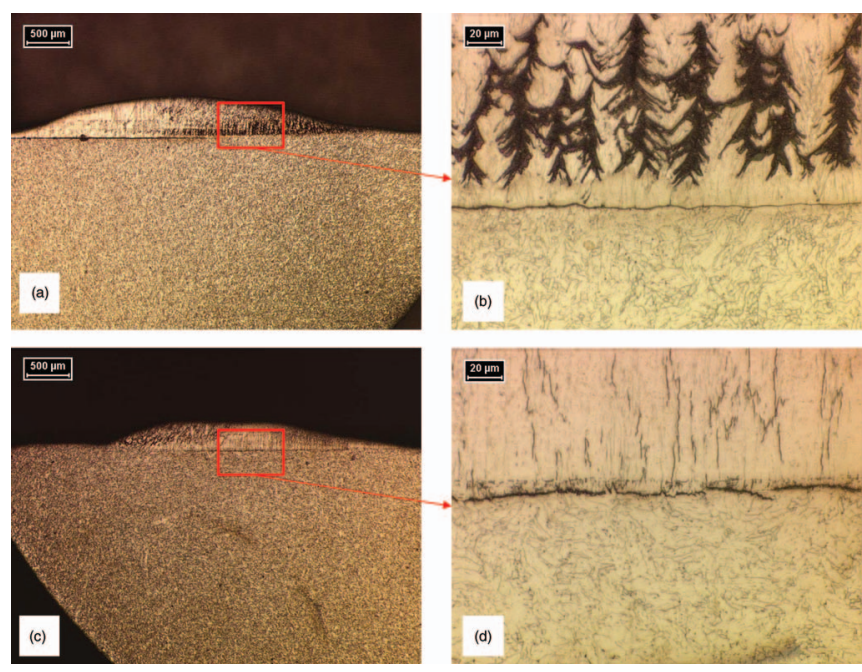

FIG. 2. (Color online) Micrograph of the Mo-cathode of the ISIS Penning source, the region facing the hydrogen injection (a) shows a dendritic growth structure (b) and the one facing Cs-injection (c) a column-like growth pattern (d). Cracks are visible between bulk and the deposited layers.

in deformed area was measured and hints to the origin of the release of Mo-flakes.

\section{BNL'S MAGNETRON ION SOURCE}

BNL's magnetron ${ }^{3}$ routinely operates at $6 \mathrm{~Hz}$ and delivers $\mathrm{H}^{-}$pulses up to $100 \mathrm{~mA}$ at $35 \mathrm{kV}$. On the electrodes of an ion source successfully operated during at least two years, wear traces are visible on the cathode, the front anode plate, and the tungsten tip of the puller electrode. No electron dump is required in view of the very favorable $\mathrm{e} / \mathrm{H}^{-}$ ratio which is below 1 , and the low duty factor $(0.5 \%)$. An upgrade to $45 \mathrm{kV}$ as would be required to operate a magnetron as Linac4 ion source requires understanding of the origin of the observed wear. Simulations of the BNL magnetron beam extraction were done using the ion optical computer simulation package IBSimu. ${ }^{4}$ The geometry includes the cathode, the anode, and the puller electrode. The objective is to observe the extracted beam behavior and simulate the conditions that lead to the damage observed on these elements after extended operation. The extracted $\mathrm{H}^{-}$beam current density is set to $1.6 \mathrm{~A} / \mathrm{cm}^{2}$, resulting in a current of $100 \mathrm{~mA}$. The electron to $\mathrm{H}^{-}$ratio is $1 / 2$ to match the working conditions. ${ }^{3} \mathrm{~A}$ (a)

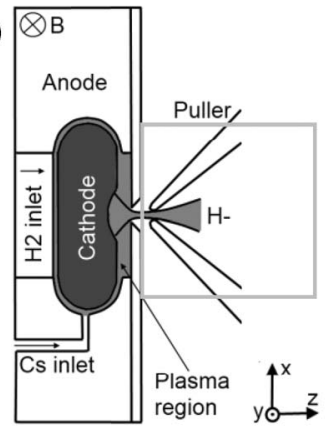

(b)

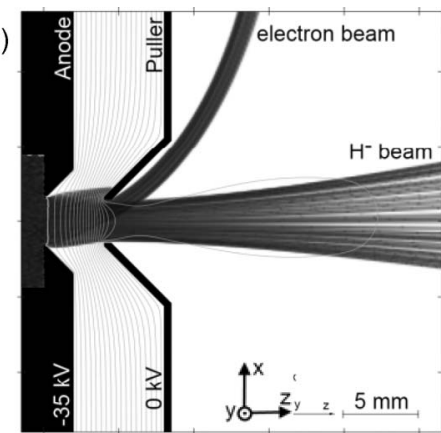

FIG. 3. (a) BNL magnetron scheme with highlighted simulated area; (b) simulated $\mathrm{H}^{-}$beam and electron extraction. 

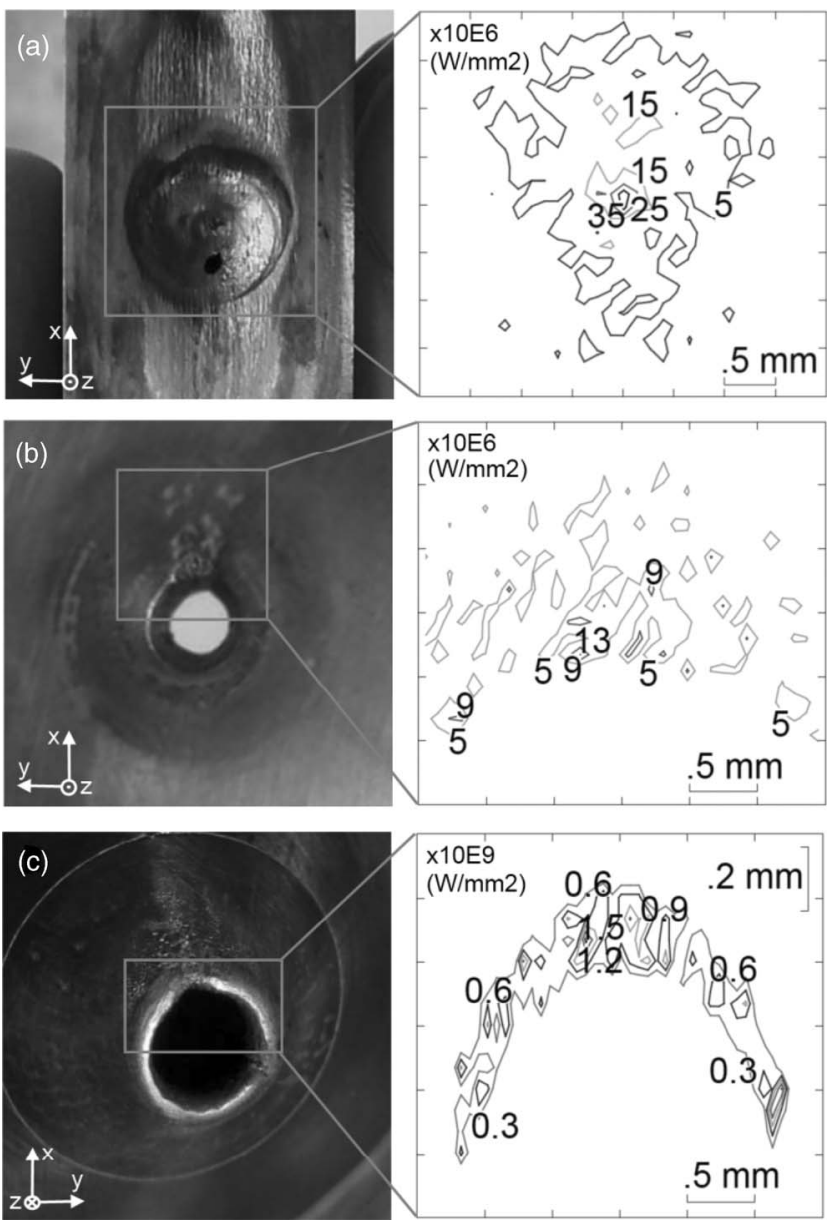

FIG. 4. Pictures and corresponding power density isolines of: (a) positive ions on the cathode dip, (b) positive ions on the anode surface, and (c) electrons and $\mathrm{H}^{-}$ions on the puller electrode tungsten tip.

three-dimensional magnetic field map was calculated with OPERA (Ref. 5) using the known magnet geometry and adjusting the peak field to $900 \mathrm{G}$. This field map is imported and used in the simulations.

As a result of the simulation, it is noted that the extracted $\mathrm{H}^{-}$beam is transmitted at close to $100 \%$ through the puller electrode and that the electrons, whose trajectories are bent by the magnetic field, are largely dumped on the tungsten tip of the puller electrode (Figure 3). The current of $30 \mathrm{~mA}$ dumped on the W-puller tip corresponding to $60 \%$ of the coextracted electron current. The location of the interaction area in the simulation coincides with the observed electrode damage. The software package includes the creation of positive ions within the extraction region, i.e., originating from ionization of Cs vapors (or rest gas particles largely dominated by hydrogen). Once ionized, the resulting positive ions will travel backwards in direction of the anode. A Cs-current of $6 \mathrm{~mA}$ is arbitrarily set in the simulation only aiming at qualitative illustration of the process. The Cs-ions hit the cathode at a very concentrated point, close to its central dip. This may lead via sputtering of Mo-atoms to the formation of a hole comparable to the one observed experimentally (Figure 4(a)). On the vacuum side of the plasma electrode, a current of $3 \mathrm{~mA}$ of Cs ions is assumed; its impact is distributed on a larger area and its peak power density accordingly reduced (Figure 4(b)). The deposition profile matches the observed traces likely due to sputtering. The power density of the incoming electrons on the puller electrode surface reaches a maximum power density of $1.5 \times 10^{9} \mathrm{~W} / \mathrm{m}^{2}$ (Figure $4(\mathrm{c})$ ).

\section{DISCUSSION, CONCLUSION, AND OUTLOOK}

Based on the observation of two of the most successful cesiated $\mathrm{H}^{-}$ion sources worldwide, we conclude that sputtering and pulsed electron energy deposition are the leading electrode wear mechanisms. Despite a very favorable e $/ \mathrm{H}^{-}$ratio, a fraction of the co-extracted electrons is driving the wear mechanism of BNL's $35 \mathrm{kV}$ puller electrode. Qualitative description of the wear mechanism was possible with modern 3D beam simulation packages that demonstrated impressive flexibility. Cesium and hydrogen positive ions are the likeliest candidates at the origin of the observed sputtering.

\section{ACKNOWLEDGMENTS}

The authors would like to acknowledge the openness of the ion source teams of BNL and ISIS.

${ }^{1}$ D. C. Faircloth, J. W. G. Thomason, M. O. Whitehead, W. Lau, and S. Yang, Rev. Sci. Instrum. 75, 1738 (2004).

${ }^{2}$ V. G. Dudnikov, in Proceedings of the IV USSR National Conference on Particle Accelerators, Moscow, 1974.

${ }^{3}$ J. Alessi, in Proceedings of 20th ICFA Advanced Beam Dynamics Workshop on High Intensity and High Brightness Hadron Beams, Fermilab, 2002.

${ }^{4} \mathrm{~T}$. Kalvas, see http://ibsimu.sourceforge.net/ for reference manual, software installation, and tutorial.

${ }^{5}$ Vector Fields OPERA, Cobham plc, Wimborne, Dorset, BH21 2BJ, UK (2011). 